\title{
O Brasil e o CARICOM
}

\author{
DÉBORAH BARROS LEAL FARIAS*
}

\section{Introdução}

Nos dias de hoje, é comum o uso do termo globalização. Freqüentemente quando este assunto é trazido à tona, idéias referentes a regionalização e blocos regionais costumam acompanhar o enunciado. Dentre os diversos blocos ou agrupamentos de países, sempre são mencionados a União Européia, o NAFTA, o Mercosul. Porém, um bloco que é pouco mencionado, e muitas vezes, se o é, apenas en passant, é o bloco do CARICOM - Caribbean Community, i.e., Comunidade Caribenha.

A diminuta atenção prestada a esse grupo de 15 países, cujo PIB reunido é de aproximadamente US\$20 bilhões e cuja população é de mais de 13 milhões, torna-se especialmente grave quando ocorre em território brasileiro, dada a proximidade geográfica e diplomática entre o país e o bloco em questão. É uma situação que certamente deveria ser revisada, já que esse grupo apresenta pontos de grande interesse e potencialidades para o Brasil, tanto em aspectos políticos e estratégicos, quanto comerciais e econômicos.

Em 1978, Cleantho de Paiva Leite, em seu artigo "O Brasil e o Caribe" lamentava a constatação de que o material relativo a esse assunto era bastante escasso. Dizia na época que “(...) não existe nenhum estudo sistemático das relações do Brasil com a América Latina, nem mesmo com os Estados Unidos. As relações com os países da América Central e do Caribe não atraíram a atenção de pesquisadores brasileiros nem de estrangeiros. (...)”. ${ }^{1}$

Passados mais de vinte anos da publicação do artigo, pode-se constatar que a situação retratada mudou apenas parcialmente. É inegável que houve um extraordinário desenvolvimento na área de pesquisas Brasil - EUA. No entanto, no que se refere aos estudos de assuntos caribenhos-brasileiros, ainda hoje existe uma dificuldade considerável para encontrar publicações que tratem especificamente do tema em questão, o que reflete, com veracidade, o pouco interesse que o tema tem despertado em pesquisadores. 
O presente artigo pretende buscar entender as diretrizes de como o relacionamento entre o Brasil e a região Caribenha tem evoluído, como se encontra no momento, e avaliar possibilidades concretas para o futuro desse relacionamento, especialmente no que diz respeito a questões comerciais.

Para tal, primeiramente se definirá o que se compreende como Caribe, de modo que se possa visualizar o contexto em que se insere o CARICOM. Em seguida, será dado um panorama do bloco, com uma visão de sua formação histórica, bases institucionais e aspectos econômicos.

Após a exposição sobre o CARICOM, será possível tratar propriamente de seu relacionamento com o Brasil, bem como o de seus países membros com o Brasil; para tal serão observados aspectos históricos, diplomáticos, econômicos e políticos relativos a esses relacionamentos.

Por fim, se buscará vislumbrar perspectivas e oportunidades que se apresentam num futuro próximo tanto no que concerne o relacionamento entre os países, como entre o Brasil e o bloco do CARICOM.

\section{O Caribe e o CARICOM}

O estudo da região caribenha se defronta, de início, com a dificuldade de definir com exatidão quais os países que dela fazem parte, em face de possíveis critérios que podem ser utilizados. Num sentido estrito, o Caribe seria formado pelos territórios insulares banhados pelo Mar do Caribe. No entanto, esse critério nem sempre é utilizado, já que outros critérios, igualmente válidos, como bases culturais, condição de (in)dependência política, territoriais, etc., podem ser utilizados acarretando outras definições.

Em Relatório de 1992, a Comissão das Índias Ocidentais propôs para os Chefes de Estado do CARICOM a criação de uma Associação de Estados Caribenhos, com o objetivo de avançar a integração econômica e a cooperação funcional. A proposta foi aceita em 1992 em Port of Spain, capital de Trinidad e Tobago, e em 1994 na cidade colombiana de Cartagena das Índias foi assinada a Convenção estabelecendo a criação da ACS - Association of Caribbean States ${ }^{2}$. Com essa organização em mente, o contorno do que se entende como sendo Caribe pode ser delineado.

O quadro a seguir mostra os países que podem ser incluídos como fazendo parte do Caribe, num entendimento amplo. Basicamente estariam aí incluídos os países banhados pelo mar do Caribe. Esse critério não é preciso, já que uma análise detalhada imediatamente aponta para falhas, como o fato de se incluir aí El Salvador, que não tem contato com esse Mar do Caribe e faz parte da ACS. No entanto, ele consegue razoavelmente apresentar os países que tem aspectos importantes para serem considerados como caribenhos. 


\section{Quadro 1 \\ Países que fazem parte do Caribe}

\begin{tabular}{|c|c|c|}
\hline & ANTÍGUA E BARBUDA & Angilla (GB) \\
\hline & BAHAMAS & Aruba (Países Baixos) \\
\hline & $\underline{\text { BARBADOS }}$ & Cuba \\
\hline & DOMINICA & Curaçao (Países Baixos) \\
\hline & GRANADA & Guadalupe (FR) \\
\hline & $\underline{\text { HAITI }}^{3}$ & Ilhas Cayman \\
\hline CARIBE & JAMAICA & Ilhas Virgens (EUA) \\
\hline ("ANTILHAS") & MONTSERRAT (GB) & Ilhas Virgens (GB) \\
\hline & SANTA LÚCIA & Martinica (FR) \\
\hline & SÃO CRISTÓVÃO E NÉVIS & Porto Rico (EUA) \\
\hline & SÃO VICENTE E GRENADINES & $\underline{\text { República Dominicana }}$ \\
\hline & TRINIDAD E TOBAGO & $\begin{array}{l}\text { Saint Martin (Países } \\
\text { Baixos) }\end{array}$ \\
\hline & & Turks e Caicos (GB) \\
\hline & BELIZE & Honduras \\
\hline AMÉRICA CENTRAL & $\underline{\text { Costa Rica }}$ & Nicarágua \\
\hline & $\underline{\text { El Salvador }}$ & Panamá \\
\hline & Guatemala & \\
\hline & GUIANA & Guiana Francesa (FR) \\
\hline AMÉRICA DO SUL & SURINAME & Venezuela \\
\hline & Colômbia & \\
\hline AMÉRICA DO NORTE & México & \\
\hline
\end{tabular}

Fonte: www.acs.org

Observações:

1. Os países acima indicados em letras maiúsculas são membros do CARICOM.

2. Os países sublinhados fazem parte da Associação de Estados Caribenhos (ACS).

3. O Caso do Haiti é peculiar: a República de Haiti já satisfez todas as condições requeridas pela Conferência de Chefes de Governo para o CARICOM, faltando o depósito com o Secretário Geral de um instrumento apropriado de ascensão. Quando essa formalidade mencionada for completada, o Haiti se tornará um membro pleno do CARICOM. 


\section{O CARICOM}

Retrospecto histórico

O Bloco do CARICOM - Caribbean Community - foi oficialmente estabelecido e efetivado em 1973, com o Tratado de Chaguaramas, tendo como membros iniciais Barbados, Jamaica, Guiana, e Trinidad e Tobago. Porém, as negociações datam de pelo menos quinze anos antes da assinatura do documento na cidade trinitária.

Em 1958, surgiu a Federação das Índias Ocidentais, tendo se originado sob a influência britânica e implementada "de baixo para cima", sem levar em conta aspectos específicos políticos e econômicos relativos aos Estados caribenhos envolvidos. A West Indies Federation durou somente até 1962, basicamente em decorrência de tendências nacionalistas entre os países e falta de privilégios tarifários, já que nem mesmo a União Aduaneira chegou a ser instituída. A independência da Jamaica e de Trinidad e Tobago da Comunidade Britânica em 1962 também foi fator de diluição desse arranjo.

Em 1965, foi estabelecido um outro Tratado, o de Dickenson Bay (Antígua), entre Antígua e Barbuda, Barbados e Guiana, criando a CARIFTA: Caribbean Free Trade Association. Posteriormente, iriam fazer parte do bloco: Anguilla, Dominica, Granada, Jamaica, São Cristóvão e Névis, Santa Lúcia, Montserrat, São Vicente e Grenadines, e Trinidad e Tobago. O CARIFTA não logrou êxito em seu empreendimento, não ocorrendo nem o fluxo nem a coordenação de políticas relativas a capitais, mão-de-obra, indústria, agricultura, entre outros temas propostos. No entanto, ele foi visto por muitos chefes de Estado da região como um passo importante para a formação de um futuro Mercado Comum Caribenho.

Em 1970, com a possibilidade da entrada da Grã Bretanha na Comunidade Econômica Européia, os Estados do CARIFTA perceberam mais claramente a vulnerabilidade da dependência relativa à esse país. No final de 1972, decidiu-se ir adiante com a idéia da criação do Mercado Comum Caribenho, dentro de uma Comunidade Caribenha, e em Agosto de 1973 entra em vigor o Tratado de Chaguaramas, assinado pelos quatro países independentes já mencionados: Barbados, Jamaica, Guiana, e Trinidad e Tobago. Vinte e cinco anos depois, o número de países havia subido para quinze.

Um episódio importante que deve ser mencionado na história do CARICOM, quando quase ocorreu a sua extinção, ocorreu durante a primeira metade da década de 1980, especificamente em 1983, com a invasão de Granada pelas forças norte-americanas. Em 1979, cinco anos após a independência da ilha caribenha, assumiu a liderança desse país Maurice Bishop, de orientação socialista, que iniciou um processo de aproximação com Cuba e com a União Soviética. Em 
1983, radicais, também da “esquerda”, promovem um golpe e fuzilam o Primeiro Ministro Bishop. Nesse mesmo ano, ocorre a invasão norte-americana, preocupada com a consolidação de um governo comunista na ilha.

Entretanto, o principal problema para o bloco do CARICOM não se deu diretamente pela invasão externa, mas sim por conflitos internos ocorridos entre os países. Desde o início da década de 1980, a região se encontrava dividida entre os conservadores - como a Jamaica, Barbados e Dominica - e os simpatizantes do socialismo, como Granada, Guiana, e Santa Lúcia. Os contatos, como um todo, entre os líderes dos países do bloco, tornaram-se mínimos, com várias reuniões do CARICOM sendo canceladas. Antes mesmo da invasão de Granada em Outubro de 1983, a situação era extremamente delicada quanto à continuação do CARICOM.

Em um texto de Julho/Agosto de 1983, a seguinte questão é levantada numa publicação regional: "La caída del gobierno de Manley, la afinidad ideologica de Seaga ${ }^{3}$, su sucessor, com el imperialismo norteamericano y, por outra parte, la consolidación del processo revolucionario de Granada, há determinado un nuevo cuadro politico en el Caribe que hace difícil predecir el futuro del CARICOM.”

Com o assassinato de Bishop e a tomada do governo granadense por radicais, ocorre a invasão. Os conflitos políticos entre os líderes dos países membros do CARICOM tornam-se ainda mais graves. Houve apoio favorável à invasão da parte dos governos da Jamaica e de Barbados e forte oposição de Trinidad e Tobago, Guiana, Bahamas, Belize, além dos partidos de oposição de Jamaica e Barbados.

A OECS - Organization of Eastern Caribbean States - formada em 1981 por Antígua e Barbuda, Dominica, Granada, Montserrat, São Cristóvão e Névis, Santa Lúcia e São Vicente, teve um papel importante na invasão. Atkins Pope ${ }^{5}$ explica que a OECS teve um papel importante logo dois anos após a sua criação, como visto no que diz respeito à invasão de Granada pelos norte-americanos em Outubro de 1983. Os Estados Unidos ignoraram o Tratado do Rio e a OEA e seguiram uma provisão da OECS (da qual esse país não era signatário) como justificativa legal para a intervenção, tendo persuadido a OECS a querer intervenção militar em um dos seus países membros - Granada. Alguns países membros da OECS se envolveram na invasão, no entanto, nem todos os países membros da organização apoiaram a ação, o que acarretou uma profunda divisão, tanto dentro da OECS quanto dentro do CARICOM.

De acordo com Howard Wiarda ${ }^{6}$, um dos primeiros países a "reagir" ante a invasão foi o Suriname que, poucas horas após a invasão, anunciou na televisão que o embaixador cubano teria seis dias para sair do país e que 25 diplomatas e oito consultores cubanos deveriam também sair do país. O Suriname havia desenvolvido uma aproximação com o regime de Castro, através de laços 
econômicos, culturais e militares; no entanto, após a invasão de Granada, o governo do General Bouterse passou a temer que os cubanos estivessem exercendo influência demais no seu país, e temeu que acontecesse à ele e ao seu governo o mesmo que acontecera com Bishop e a conseqüente invasão das tropas americanas, já que o General acreditava que os cubanos tiveram responsabilidade no derramamento de sangue granadense. No entanto, Wiarda coloca que, mesmo que as ações de Bouterse tenham coincidido com a invasão e por elas tenham sido influenciadas, a decisão de reduzir a presença cubana já havia sido decidida antes de 25 de Outubro de $1983 .^{7}$

A situação dentro do CARICOM só se amenizou nos idos de 1985-86; no entanto, essa discórdia gerou desconfianças mútuas que certamente tiveram seu efeito no desenrolar dos trabalhos de consolidação do bloco.

\section{A base institucional}

Em termos gerais, o CARICOM tem como meta a integração e a coordenação das políticas e interesses dos seus Estados membros - especialmente no âmbito externo. Tendo como vizinhos grandes blocos econômicos - o NAFTA e o Mercosul - o CARICOM busca um maior poder de voz para seus representantes, relativamente ao que teriam se seus membros agissem individualmente, de modo a buscar um maior poder de barganha nas diversas instâncias de negociação.

São países que apresentam problemas semelhantes: pouca produção em escala, dependência dos mercados externos, pequena área territorial, problemas sociais como desemprego e pobreza, pouca diversificação na pauta de exportação, etc. Além disso, contam com um aspecto histórico comum de passado europeu com a presença marcante da Grã Bretanha e dos seus modelos de instituições políticas - tendo como uma das línguas oficiais o inglês. A população é composta por um misto de descendentes de negros escravos da época das plantações de açúcar, brancos europeus, e, num número considerável de países, a presença de asiáticos, sobretudo indianos, entre outros traços comuns.

De acordo com a comunicação oficial do CARICOM ${ }^{8}$, alguns dos benefícios do Mercado e Economia Comuns do bloco seriam os seguintes:

- Aumento da produção de comércio de bens e serviços para um mercado superior a 13 milhões de pessoas (incluindo o Haiti);

- Ganho na competitividade dos produtos, com melhoras tanto na qualidade quanto no preço;

- Melhoria nos serviços de transporte e comunicação entre os indivíduos dos países membros; 
- Oportunidade de escolha de país onde trabalhar e estudar dentro da Comunidade;

- Aumento de ofertas de emprego e melhoria no padrão de vida. ${ }^{9}$

Certamente, alguns desses benefícios podem ser questionados quanto à sua viabilidade, no entanto, não há dúvidas que esses Estados, ao se reunirem, potencializam seus ganhos no plano externo, especialmente quando se trata de peso político dentro de organismos internacionais, já que representam um número bastante significativo de votos, gerando um maior poder de negociação com outros países.

Quanto aos objetivos gerais do CARICOM, eles são essencialmente três: I. Cooperação econômica, através do Mercado e Economia Comuns Caribenho; II. Coordenação de Política Externa entre os Estados Membros independentes; III. Cooperação e Serviços comuns em assuntos como saúde, educação, cultura, comunicação, e relações industriais.

Os órgãos máximos do CARICOM são o encontro dos Chefes de Governo e do Conselho Ministerial; o primeiro representa a autoridade máxima, enquanto que no outro é onde se buscam alcançar o consenso em questões regionais e de política.

Conforme mencionado anteriormente, o CARICOM é formado por 15 países. No entanto, numa perspectiva maior, apresentam algumas peculiaridades que valem ser mencionadas. Uma dessas peculiaridades é o caso das Bahamas que, apesar de pertencerem à Comunidade, não pertencem ao Mercado Comum. Uma razão para essa exclusão reside no fato das Bahamas, apesar de serem um paraíso fiscal, com intenso fluxo turístico e PIB relativamente alto, não se caracterizam como grande produtora de produtos comercializáveis, tendo assim suas receitas oriundas basicamente de serviços, não de comércio, agricultura ou indústria ${ }^{10}$. Possivelmente por essa razão, ela não pertence ao Mercado Comum, posto que o objetivo desse é primordialmente aumentar o fluxo de comércio de bens na região ${ }^{11}$.

Uma outra justificativa para essa posição das Bahamas não se apresenta de forma "oficial”, mas sim de modo informal, é que as Bahamas não teriam interesse em ingressar no Mercado Único por temerem repartir sua receita proveniente do turismo - principal atividade econômica da ilha - com outras ilhas vizinhas. ${ }^{12}$

Montserrat é outro país que tem uma característica peculiar: é o único membro não-independente do CARICOM, sendo ainda uma dependência britânica. Tendo apenas 102 km² ainda se recupera da explosão do vulcão Chances Peak em 1995, essa ilha - que antes da explosão possuía cerca de dez mil habitantes - hoje em dia é habitada por pouco mais de 3.200 (três mil e duzentas) pessoas. O governo 
britânico deverá ter feito investimentos de aproximadamente US\$ 125 milhões no período 1998-2001. O futuro do desenvolvimento da ilha é incerto, já que especialistas prevêem que a área ainda poderá estar ameaçada por erupções. Portanto, a participação de Montserrat no âmbito do CARICOM nos próximos anos tenderá a ser mais pro forma, provavelmente se relacionando com os países do bloco apenas como recebedor de ajuda ${ }^{13}$.

Existem também outros países ligados ao bloco, em situação de Observadores ou de membros Associados. No primeiro bloco estão: Anguilla, Antilhas Holandesas, Aruba, Bermuda, Colômbia, Ilhas Cayman, México, Porto Rico, República Dominicana, Venezuela; no segundo estão as Ilhas Virgens Britânicas, e as Ilhas Turks e Caicos (GB).

Além dessas categorias, dentro do Mercado (onde se excetuam as Bahamas), existe uma subdivisão entre os que são considerados os Países Mais Desenvolvidos e Menos Desenvolvidos: os Mais são Barbados, Guiana, Jamaica, Suriname, e Trinidad e Tobago, todos os outros pertencendo à condição de menos desenvolvidos. ${ }^{14} \mathrm{O}$ intuito dessa subdivisão seria estimular o desenvolvimento da região, tendo os países mais desenvolvidos à frente, dados os seus maiores recursos, assim abrindo caminhos e criando oportunidades para os outros países.

\section{Quadro econômico e situação presente do CARICOM}

O Mercado Comum do Caribe faz parte da Comunidade Caribenha, cujo objetivo principal é a maior integração comercial entre os países; além desse, a cooperação e coordenação de políticas externas também são objetivos do Mercado. No entanto, a integração econômica não tem ocorrido de forma intensa. No geral, o maior obstáculo para essa integração tem sido a pequena dimensão dos mercados e da base de exportação dos países do bloco.

O principal mecanismo de integração econômica tem sido discutido no âmbito do Mercado Comum Caribenho com base na Tarifa Externa Comum. Nessa área do Mercado Comum, através do Acordo de Nassau, assinado nas Bahamas em 1984 se estabeleceu uma Tarifa Externa Comum, que, no entanto, nunca chegou a se aplicar por completo. Em 1990, se concordou com outra Tarifa Externa Comum, que revisada em 1992, instituiu um cronograma para entrar em funcionamento em 1998. Os países da OECS são os que mais tiveram ou tem dificuldade de se adaptar à essa Tarifa Externa Comum, já que em muitos desses países os recursos fiscais vindos de tarifas representarem valores significativos.

Quanto ao relacionamento comercial com os outros países da América, com exceção dos Estados Unidos e do Canadá, é possível afirmar que se apresenta mais desenvolvido frente aos países do Grupo dos Três: México, Colômbia e Venezuela. Fora esses, o intercâmbio é tímido. 
Excetuando-se os países mais desenvolvidos do bloco - Trinidad e Tobago, Barbados, Suriname, Guiana e Jamaica - a pauta dos países é extremamente reduzida, em muitos casos chegando a ser caracterizada por monoculturas. $\mathrm{O}$ produto de muitas das ilhas nessa situação é a banana, de cuja exportação são dependentes e cujo destino é basicamente a União Européia. ${ }^{15}$

O volume de comércio internacional per capita dos países da região é considerado alto, o que parece lógico, devido à limitada pauta de produção dos países, especialmente com relação aos produtos de indústria de bens de produção e à dificuldade de recursos naturais diversificados e de sustentação de indústrias de escala. No entanto, mesmo importando relativamente muito, a maior parte das exportações é realizada para países fora da região; Trinidad e Tobago é o único país da comunidade a apresentar um balanço consistentemente positivo no comércio intra-CARICOM. A Enciclopédia Britannica ao comentar sobre o comércio intraCARICOM faz as seguintes observações ${ }^{16}$ :

- Os maiores parceiros comerciais dos países do bloco são os Estados Unidos e os países europeus; o Canadá também está presente, numa associação já relativamente antiga, através do acordo CARIBCAN;

- O comércio entre os países caribenhos é pequeno em razão dos limitados recursos industriais e do padrão econômico monocultural. Bens e commodities comercializados dentro da economia caribenha são poucos: arroz da Guiana; madeira de Belize; óleo refinado de Trinidad e Curaçao; sal, fertilizantes, óleos vegetais e gorduras das ilhas orientais; e alguns produtos manufaturados;

- A falta de capital e o volume limitado de recursos no geral têm desencorajado o desenvolvimento industrial, enquanto a mão de obra barata e os incentivos fiscais têm atraído algumas indústrias;

- O principal destino da maior parte dos produtos da região tem sido os Estados Unidos e o Canadá. Estes países importam principalmente banana, açúcar, café, bauxita, rum e óleo;

- Praticamente todo comércio entre o Atlântico e o Pacífico passa pelo Caribe, através do Canal do Panamá.

Os quadros a seguir ajudam a mostrar como tem caminhado a integração comercial dentro do CARICOM $^{17}$ :

\section{Quadro 2}

Exportações totais e inter-regionais do CARICOM (Em milhões de dólares, FOB e percentagens)

\begin{tabular}{l|c|c|c|c|c|c|c|c|c}
\hline & 1990 & 1991 & 1992 & 1993 & 1994 & 1995 & 1996 & 1997 & 1998 \\
\hline Exportações Total & 4.762 & 4.771 & 4.875 & 4.837 & 5.933 & 6.211 & n.d & n.d & n.d \\
\hline Exp dentro CARICOM & 555 & 463 & 467 & 551 & 587 & 815 & n.d & n.d & n.d \\
\hline \% Exp CARICOM/Total & 11,7 & 9,7 & 9,6 & 11.4 & 9,9 & 13,1 & n.d & n.d & n.d \\
\hline
\end{tabular}

Fonte: BID. Integração e Comércio na América. Dezembro 1998. 


\section{Quadro 3 \\ Exportações totais e inter-regionais do CARICOM \\ (Variação Percentual)}

Às vésperas da virada do milênio, o CARICOM ainda se empenha no caminho de uma integração cada vez maior entre seus membros - especialmente no que diz respeito ao aspecto comercial e à diminuição de barreiras tarifárias e não-tarifárias.

No que diz respeito à coordenação de Política Externa, existe uma unidade de posicionamento dos países do bloco em vários foros:

- Convenção de Lomé (União Européia);

- Caribbean Basin Iniciative (Estados Unidos da América);

- CARIBCAN (com o Canadá);

- AEC (Associação dos Estados Caribenhos);

- Acordos com Venezuela (desde 1992) e Colômbia (desde 1994) sobre comércio e investimento, dando tratamento especial aos mercados caribenhos;

- Mercado Comum Centro Americano, tendo em vista a formação de uma Zona de Livre Comércio (primeira reunião em Honduras, 1992). Quanto a esse acordo, no caso de sua concretização ou de uma fusão entre os dois blocos, criar-se-ia um bloco nada desprezível, com uma população de cerca de 55 milhões de pessoas ${ }^{18}$;

- ALCA, Organização das Nações Unidas e Organização dos Estados Americanos.

No entanto, ao que parece, a maioria dos entendimentos com esses países e blocos não vem surtindo o efeito desejado que seria o aumento das exportações. Quanto ao relacionamento com o MERCOSUL, as negociações ainda estão em uma fase preliminar, distantes de proporcionar algum tipo de consolidação no relacionamento.

\section{Do relacionamento do Brasil com o CARICOM e seus países membros}

Assim como afirma o posicionamento oficial do Ministério das Relações Exteriores, as relações com o Caribe têm sido amistosas e cordiais, mesmo que historicamente de baixa intensidade. Os países “caribenhos” - cabe mencionar que não há uma especificação a respeito de quais seriam exatamente esses países - teriam tradicionalmente se voltado para os Estados Unidos e, nos últimos anos, 
estariam buscando uma maior aproximação com a América Latina, especialmente com o Mercosul, acarretando maiores oportunidades para a política externa brasileira, levando-se em conta o mercado potencial da região ${ }^{19}$.

Ao se avaliar o Brasil frente ao CARICOM, vários aspectos saltam aos olhos. O Brasil é repleto de dados superlativos. É o quarto maior país do mundo em extensão. Está entre as quinze maiores economias e populações do mundo. Quando se compara esses números com os do CARICOM ${ }^{20}$, o Brasil aparece como um verdadeiro gigante, em tamanho e em peso. O quadro abaixo apresenta uma visão mais explícita dessa realidade.

\section{Quadro 4}

Quadro comparativo entre o Brasil e o CARICOM

\begin{tabular}{l|c|c}
\hline & BRASIL & CARICOM \\
\hline Área territorial $\left(\mathrm{km}^{2}\right)$ & & $\begin{array}{c}\text { (área insular: 83.748) } \\
\text { (Guiana: } 210.970) \\
\text { (Suriname: } 163.820) \\
\end{array}$ \\
\hline População (dados de 1996) & 8.511 .965 & 458.538 \\
\hline PIB (1995) em bilhões de US\$ & 747.079 .573 & 13.725 .219 \\
\hline PIB per capita (1995) em US\$ & 4.743 & 20.519 \\
\hline IDH (1996) & $0,809 * *$ & $3.455^{*}$ \\
\hline
\end{tabular}

Fonte: Almanaque Abril, 1998 e PNUD, 1995.

*média dos quinze países

**PNUD

No entanto, talvez não tenha sido essa disparidade a causa da baixa intensidade do interesse brasileiro. Antes de 1992, o país era ainda razoavelmente fechado para mercados externos, de modo que não era apenas com o CARICOM que o Brasil mantinha um baixo relacionamento comercial. Outro fator importante, sem dúvida, é a participação brasileira na consolidação do Mercado Comum do Sul, MERCOSUL. Desde 1991, o país tem olhado para o sul, vislumbrando como parceiros comerciais a Argentina, o Uruguai, e o Paraguai. Com o aumento dos relacionamentos " $4+1$ ”, com o Chile, Bolívia e Venezuela (apesar de ainda em estágios iniciais), talvez se esteja caminhando para uma possível visão mais ao norte, em um contexto em que o CARICOM se encontraria. No momento, porém, isso não é mais do que uma possibilidade.

Durante a VIII Reunião da Conferência dos Chefes de Governo do CARICOM, realizada em Antígua e Barbuda em 1997, o Ministro das Relações Exteriores do Uruguai, Sr. Álvaro Ramos Trigo, comentou sobre o diminuto 
relacionamento existente entre o CARICOM e o MERCOSUL, bem como entre os países pertencentes aos blocos em um nível bilateral. Um caminho para reverter essa situação estaria na celebração de acordos entre os dois blocos, da mesma forma que já tem sido firmados com outros países e blocos. Nas palavras do senhor ministro: "El diseño no discriminatorio de MERCOSUR se vê reflejado también en los acuerdos de associación celebrados recientemente entre com Chile, Bolivia y la Unión Europea, y en las amplias negociaciones que estamos realizando actualmente com los países del Pacto Andino y com Mexico. En nuestra opinión, los próximos pasos dentro de este proceso deberían incluir a los países del Caribe y Centroamérica”21

Quando - e se - essa consolidação acontecerá, no momento é incerto. Cabe ao tempo - e aos respectivos Governos - darem a resposta.

\section{Retrospectiva histórica}

Historicamente, o Brasil nunca chegou a ter grandes momentos de relacionamento com os países da região caribenha. Existe uma explicação razoável para essa ausência: diferentemente dos países da América do Sul, que tiveram sua independência firmada no século XIX, até a metade da década de 1960, praticamente todos os países da região ainda não eram independentes - daí, se houvesse interesses brasileiros relativos a eles, não se trataria diretamente com eles, mas sim com o país controlador da dependência. Portanto, análises anteriores à esse período, não tratam de países independentes, mas sim de colônias.

Num próximo passo, se considerarmos o período histórico onde esses países - aqui centrando especificamente nos países do CARICOM - alcançaram sua independência, veremos que estamos no meio do período da Guerra Fria, com a preponderância dos conflitos Leste-Oeste, Comunismo versus Capitalismo como sistema dominante do mundo.

Ao efetuar uma análise do relacionamento do Brasil com os países do CARICOM, impreterivelmente há de se inserir essa dimensão de conflito ideológico mundial. Estando os países tratados no continente americano, é inegável a forte influência da ideologia capitalista encabeçada pelos Estados Unidos da América. O relacionamento do Brasil com o Caribe (e logo, com os países do CARICOM) foi, especialmente até o fim dos governos militares em 1985, em grande parte condicionado pelo relacionamento brasileiro com os Estados Unidos.

A Revolução Cubana em 1959, o seguido rompimento diplomático com os Estados Unidos e o alinhamento da ilha com o regime soviético, fizeram com que a região caribenha passasse a ser vista com outros olhos. O receio norte-americano de que Cuba servisse como exemplo para os outros países da região faz com que a importância geopolítica do Caribe seja estratégica. 
Segundo Atkins Pope, à época da invasão de Granada, era a credibilidade dos Estados Unidos perante o mundo que estava em jogo, já que um possível triunfo das forças hostis soviéticas em uma área tão próxima aos norte-americanos teria um impacto devastador no posicionamento desse país no contexto da Guerra Fria.

Em um texto de 1972, Lincoln Gordon"22 vai além e diz: "From the security viewpoint, if not politically, the Caribbean is very widely regarded by the public opinion in the United States as necessarily an American lake”.

Além da questão ideológica envolvendo a região caribenha, existiu outro fator que contribuiu para o grande interesse norte-americano no Caribe: o transporte entre o Canal do Panamá e os Estados Unidos, passando necessariamente pelo Mar do Caribe. Em 1982, o Presidente dos EUA, Ronald Reagan, fez um pronunciamento (provavelmente válido já há vários anos), no qual colocava a região caribenha como sendo uma artéria vital estratégica e comercialmente para os Estados Unidos, com quase metade do comércio exterior norte-americano, dois terços do óleo importado e mais da metade da importação de minérios estratégicos passando pelo Canal do Panamá ou pelo Golfo do México. E alertava: “...Make no mistake: the well being and security of our neighbours in this region are in our vital interest..."23

Diferentemente dos Estados Unidos, o Brasil nunca foi dependente do transporte pelo Canal do Panamá, muito menos pelo Golfo do México, o que talvez explique, pelo menos em parte, a reduzida atenção direcionada ao Mar do Caribe.

Dentro do CARICOM, dado os interesses brasileiros em evitar conflitos fronteiriços, preocupação diplomática existente desde os tempos do Barão do Rio Branco, os países com quem o Brasil inicialmente buscou manter um maior contato foram a Guiana, ex-colônia Inglesa, independente em 1966; e o Suriname, antiga Guiana Holandesa, independente em 1975.

Talvez seja possível compreender essa preocupação maior com a região fronteiriça do Brasil observando a reação brasileira quanto à invasão de Granada. O posicionamento oficial do Brasil foi de repúdio à atitude norte-americana, com base na argumentação de que o Brasil, junto com o México e a Venezuela, não aceitariam a versão norte-americana de que seria uma questão de disputa política entre Leste e Oeste. ${ }^{24}$ No entanto, no que diz respeito à reação do governo de Bouterse no Suriname em relação à Cuba, por decorrência e influência da invasão norte-americana a Granada, o Brasil parece ter se posicionado de forma favorável ao General. Wiarda ${ }^{25}$ afirma em seu trabalho que existiriam comentários de que o Brasil, posicionado na fronteira ao sul do Suriname, estaria temeroso quanto à presença cubana ou de "esquerda” tão próxima ao seu território, tendo portanto exercido pressão sobre Paramaribo.

A idéia de pressão brasileira para que o governo do Suriname diminuísse a presença cubana em seu território, mesmo que não implicasse em um apoio 
brasileiro à atitude norte-americana (o objetivo de diminuição do “comunismo" na região caribenha), especialmente no que poderia dizer respeito aos países fronteiriços ao Brasil, talvez não tenha sido de todo malvisto por esse país. No entanto, essa idéia é apenas uma possibilidade e não um fato comprovado.

Outra hipótese é que a condenação brasileira à invasão norte-americana, talvez se relacionasse não propriamente a um apoio à Granada, mas a uma apreensão de que o mesmo pudesse ocorrer no Suriname, levando a um controle militar norte-americano em um país na fronteira com o Brasil. Daí o Brasil ter dado bastante atenção a esse país no período do final dos anos 70, início dos anos 80, especialmente através de missões militares e da Operação Venturini. Ricupero ${ }^{26}$ resume a questão comentando que "no episódio pouco conhecido e estudado do Suriname, país limítrofe, o Brasil será o protagonista decisivo ao tomar a iniciativa de oferecer ao governo militar daquele país o que será por muitos anos sua única fonte não-comunista de colaboração econômica, técnica e militar.” Assim, a ação brasileira afastaria o risco de uma intervenção americana, antes de Granada, o que abriria o caminho para a sua futura redemocratização.

Mesmo apesar da relativamente curta distância geográfica entre o Brasil e os outros países caribenhos (insulares e não-fronteiriços), a distância política parece sempre ter sido enorme. O relacionamento brasileiro com esses países do CARICOM apareceu como sendo de interesse marginal. A fronteira de interesses brasileiros, relativos à América abaixo dos Estados Unidos, estava traçada basicamente de acordo com as fronteiras geográficas da América do Sul.

Paulo Vizentini ${ }^{27}$ posiciona a política externa do Governo Reagan (198088) para as Américas como sendo "norteada pela obsessão norte-americana em derrotar o chamado expansionismo soviético-cubano na América Central e Caribe, pela ênfase [da política externa] nas relações bilaterais; e pelo simultâneo esvaziamento das novas formas de cooperação multilateral. Isto era particularmente acentuado quanto à tentativa de limitação diplomática de potências médias como o Brasil”.

E continua a comentar sobre o posicionamento brasileiro nessa questão, junto com as questões relativas aos movimentos "revolucionários” na América Central e no Caribe, onde o Brasil buscava mudar o eixo da discussão de LesteOeste, como desejavam os Estados Unidos, para a visão de um conflito Norte-Sul. Para o autor, o Governo Figueiredo (1979-85) descartou a possibilidade de uma nova parceria privilegiada com Washington, assim como a tese da nova guerra fria, pois, punha em risco a política de relações prioritárias bilaterais e multilaterais como país do Terceiro Mundo, no âmbito do diálogo Norte-Sul. O Itamaraty não tinha interesse em perder a autonomia e buscava retirar a crise da América Central e do Caribe do âmbito da confrontação Leste-Oeste, reconhecendo sua singularidade e a possibilidade de solução negociada entre as forças internas do 
conflito. Ainda assim, a diplomacia do Universalismo evitava atitudes radicais e um possível confronto diplomático com a Casa Branca. ${ }^{28}$

Com o fim do regime militar, há uma mudança de enfoque quanto à região caribenha como um todo, com o governo brasileiro buscando uma aproximação mais concreta do Caribe, da América Central e de outros países da América Latina. O principal mecanismo de aproximação vem a ser a formação do Grupo do Rio.

O Grupo do Rio (GRIO), também chamado de Mecanismo Permanente de Consulta e Concertação Política, foi formado em 1986 no Rio de Janeiro. Inicialmente foi o resultado da fusão do Grupo da Contadora, que incluía México, Colômbia, Venezuela e Panamá, e o Grupo de Apoio, que era formado pela Argentina, Brasil, Peru e Uruguai. Em 1990, se juntam formalmente ao Grupo, Chile, Equador, Bolívia e Paraguai, bem como um membro rotativo do Caribe e outro da América Central.

Os objetivos oficiais do Grupo do Rio são aumentar e sistematizar a cooperação e o diálogo entre os países membros, buscando uma harmonização de posições em relação a questões que tocam os países, de modo a obter mais peso em momentos de negociação internacional, além de buscar a cooperação entre os países membros.

É importante mencionar que tanto os países caribenhos quanto os centro americanos acreditam que deveriam ter direito à mais representantes junto ao organismo. $\mathrm{O}$ argumento é justo, já que um voto centro-americano representa cinco países e um caribenho pelo menos quinze países. O posicionamento dos países dessa região estaria, assim, certamente marginalizado. Quem sabe caberia uma análise mais aprofundada pela cúpula do Grupo do Rio de forma a rever essa situação e tornar o posicionamento do Grupo mais democrático.

É, portanto, nesse contexto que basicamente se fomentaram as bases para o relacionamento entre o Brasil e os países membros do CARICOM: através da influência direta e indireta dos Estados Unidos na região caribenha e do Grupo do Rio. No entanto, existem outras searas onde os países se encontram como no Sistema Econômico Latino Americano (SELA), nas Nações Unidas (especialmente no Grupo dos 77, uma união “informal” entre mais de cem países subdesenvolvidos), na Organização dos Estados Americanos (OEA), além dos organismos de caráter mais técnico, como a Organização Mundial da Saúde, Organização Internacional do Trabalho, entre outras.

\section{Perspectiva diplomática}

Desde 1994, o Brasil tem participado, na condição de país convidado, das conferências de chefe de governo do CARICOM, que vem a ser a instância mais elevada da entidade. No entanto, esse fato parece ser o único vínculo do Brasil 
com o CARICOM como bloco, já que o contato pátrio com os países desse bloco tem se dado unicamente através de relacionamentos bilaterais.

Outro relacionamento brasileiro com os países do CARICOM no que diz respeito a um foro de aproximação é a presença brasileira nos últimos anos nas reuniões da Associação dos Estados Caribenhos no status de país observador ${ }^{29}$, conforme foi anteriormente mencionado.

A presença brasileira nessa associação parece ser importante no momento em que o Brasil busca se firmar como um global player. Ademais, todos os países independentes com os quais o Brasil faz fronteira norte se encontram presentes como membros plenos (Colômbia, Venezuela, Guiana e Suriname), o que ressalta ainda mais a importância da presença brasileira nos assuntos da região. Caso se deseje partir para uma abordagem mais abrangente, o Brasil ainda teria um motivo a mais para a justificativa de sua presença neste foro: a existência de uma fronteira marítima norte do Brasil com a região em questão, através especialmente do Estado do Amapá. Dependendo do intérprete, essa fronteira marítima norte incluiria até mesmo outros Estados brasileiros do Norte e do Nordeste.

Essa posição é encontrada num documento do Ministério das Relações Exteriores, datado de Setembro de 1996, quando o Brasil ainda solicitava a condição de observador: “Ao contrário dos demais países latino-americanos que já teriam manifestado intenções em relação ao status de observador, o Brasil apresenta características distintas quanto ao Caribe. O litoral do Amapá poderia ser considerado caribenho, grande parte do norte brasileiro é ecologicamente caribenho e, no plano demográfico, compartilhamos com o Caribe uma significativa contribuição africana." 30

No que diz respeito à representação diplomática na região, a situação é que dos quinze países pertencentes ao CARICOM, o Brasil possui embaixadas localizadas em seis deles:

- Trinidad e Tobago (também Embaixada Cumulativa de Dominica);

- Haiti;

- Barbados (Cumulativa de São Cristóvão e Névis);

- Jamaica (Cumulativa das Bahamas);

- Guiana (Cumulativa de Granada e São Vicente e Grenadinas);

- Suriname (Cumulativa de Santa Lúcia).

Os outros países membros do CARICOM possuem as Embaixadas Cumulativas em países não-membros do CARICOM, como é o caso de Belize, cuja "embaixada” brasileira está no México, Antígua e Barbuda em Cuba, e Montserrat, que por não ser independente, tem sua "representação" na embaixada brasileira em Londres. Um detalhe interessante é que tanto a Guiana quanto o Suriname estão separados em Departamentos diferentes dos outros países do 
CARICOM por fazerem fronteira com o Brasil. Isso pode levar a um entendimento de como o Brasil vê esses países: não no Caribe, mas sim na América do Sul.

No Brasil, encontram-se em Brasília as embaixadas de Trinidad e Tobago, Guiana, Suriname e Haiti. A prática de reciprocidade é bastante comum em diplomacia, no entanto, como se vê, o Brasil possui mais embaixadas entre os países do CARICOM do que embaixadas destes países em Brasília. Uma razão provável para tal situação é o custo relativamente mais alto da instalação de uma representação permanente para os países do CARICOM do que para o Brasil, dada a dimensão econômica brasileira, mesmo que se considere os recentes cortes no orçamento do Ministério das Relações Exteriores.

Muitos países do CARICOM que não possuem representação no Brasil ou tem a cumulatividade na embaixada do respectivo país na Venezuela ou ainda, no caso dos países bastante diminutos (como Santa Lúcia e Antígua e Barbuda), há apenas uma representação geral na sede das Nações Unidas.

No que concerne à questão político-diplomática, o Brasil e os países do Caribe como um todo parecem ter posicionamentos semelhantes em foros internacionais. Um exemplo do peso do bloco do Caribe e do CARICOM é visível na concentração de mais de um terço dos votos da Organização dos Estados Americanos (OEA).

Em momentos de mobilização para nomeações em organismos internacionais em que esses países atuam, o Brasil costuma pedir apoio quando necessário. No entanto, já existiram casos em que o pedido foi feito pelos caribenhos pelo apoio brasileiro, sendo a recíproca desse foi no mínimo insatisfatória, quando não negativa ${ }^{31}$.

Infelizmente, o interesse brasileiro junto ao CARICOM tem se manifestado mais em aspectos políticos do que propriamente em assuntos ligados à intensificação de relações econômicas, culturais ou de cooperação técnica, já que existem possibilidades interessantes a serem exploradas, especialmente para as regiões Norte e Nordeste do Brasil.

\section{Perspectiva econômica e política}

Apesar do Brasil importar pouquíssimo do CARICOM, provavelmente muito menos do que poderia ou deveria, tanto em valores brutos quanto relativos, ainda assim o país é um parceiro comercial relativamente bem posicionado na ótica de alguns países do bloco, especialmente aqueles que possuem uma pauta de exportação mais diversificada. As tabelas abaixo mostram o quão baixo são os valores de comércio internacional entre o Brasil e o CARICOM. 


\section{Quadro 5}

Exportação do Brasil (US\$ 1.000, FOB)

\begin{tabular}{l|c|c|c|c|c|c}
\hline & 1992 & 1993 & 1994 & 1995 & 1996 & 1997 \\
\hline Total Geral & 35.793 & 38.555 & 43.545 & 46.506 & 47.747 & n.d. \\
\hline $\begin{array}{l}\text { Para a Comunidade e Mercado } \\
\text { Comum do Caribe (CARICOM) }\end{array}$ & 87 & 111 & 126 & 152 & 143 & n.d. \\
\hline Porcentagem & 0,002 & 0,003 & 0,003 & 0,003 & 0,003 & n.d \\
\hline
\end{tabular}

Fonte: MiCT- /SECEX, 1997

Quadro 6

Importação do Brasil (US\$ 1.000, FOB)

\begin{tabular}{l|c|c|c|c|c|c}
\hline & 1992 & 1993 & 1994 & 1995 & 1996 & 1997 \\
\hline Total Geral & 20.554 & 25.256 & 33.079 & 49.663 & 53.286 & n.d. \\
\hline $\begin{array}{l}\text { Da Comunidade e Mercado Comum } \\
\text { do Caribe (CARICOM) }\end{array}$ & 28 & 14 & 52 & 71 & 22 & n.d. \\
\hline Porcentagem & 0,001 & 0,0006 & 0,002 & 0,001 & 0,0004 & n.d. \\
\hline
\end{tabular}

Fonte: MiCT - SECEX, 1997

Não é só para o Brasil que o comércio com o CARICOM pouco representa em termos relativos: considerando-se o dado que o total exportado pelo CARICOM em 1995 foi de US\$ 6.211 milhões, apenas US\$ 71 milhões vieram para o Brasil, ou seja, apenas $1,14 \%$ do total exportado ${ }^{32}$. O gráfico a seguir se refere à exportação de produtos brasileiros, especificada por país de destino dentro do CARICOM no ano de 1997.

\section{Gráfico 1 \\ Exportação de produtos brasileiros para o CARICOM}

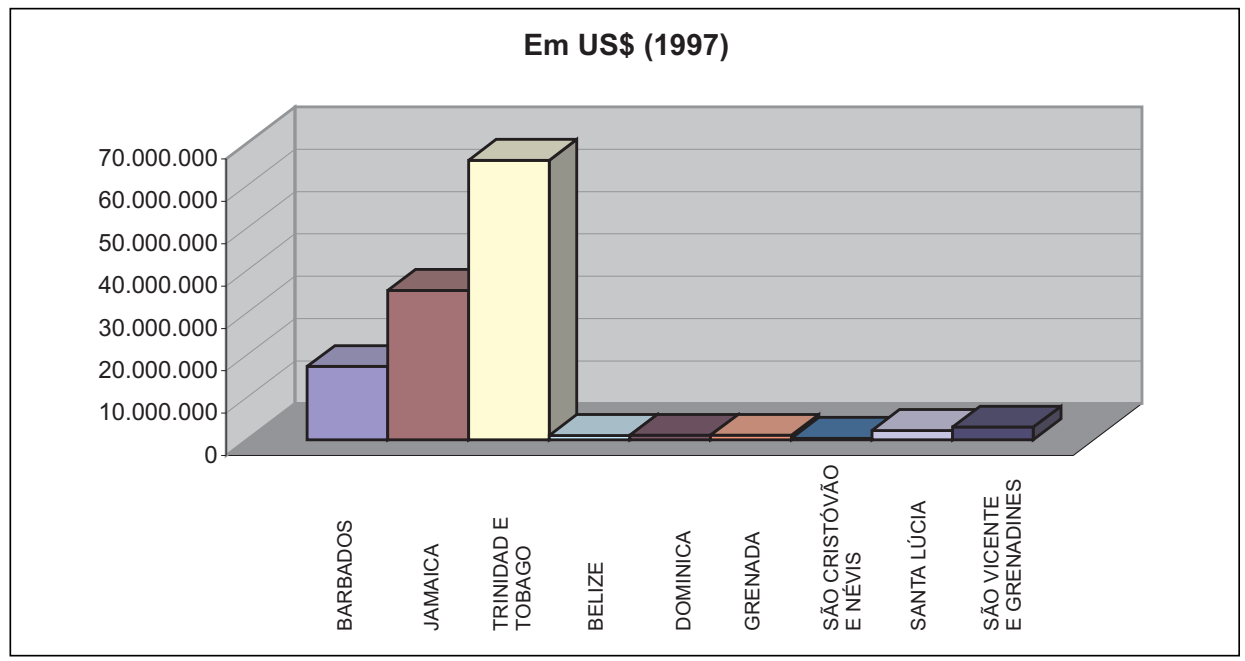


O que esse gráfico demonstra claramente é a concentração de exportações brasileiras dirigidas àqueles países considerados os mais desenvolvidos do bloco: Barbados, Jamaica e Trinidad e Tobago. Quanto aos produtos exportados, é interessante que a maior parte é constituída de produtos manufaturados ou de valor agregado considerável, e os produtos primários, como frutas, vegetais e cereais, pouco representam nesse comércio. Ao se analisar esses números, o importante é compreender que, como já foi mencionado, a maioria dos países da região tem pequena economia de escala, com um "parque industrial” pouco desenvolvido e pouco diversificado.

O gráfico a seguir é a representação percentual das exportações em questão:

\section{Gráfico 2}

\section{Exportações brasileiras para o CARICOM em \%}

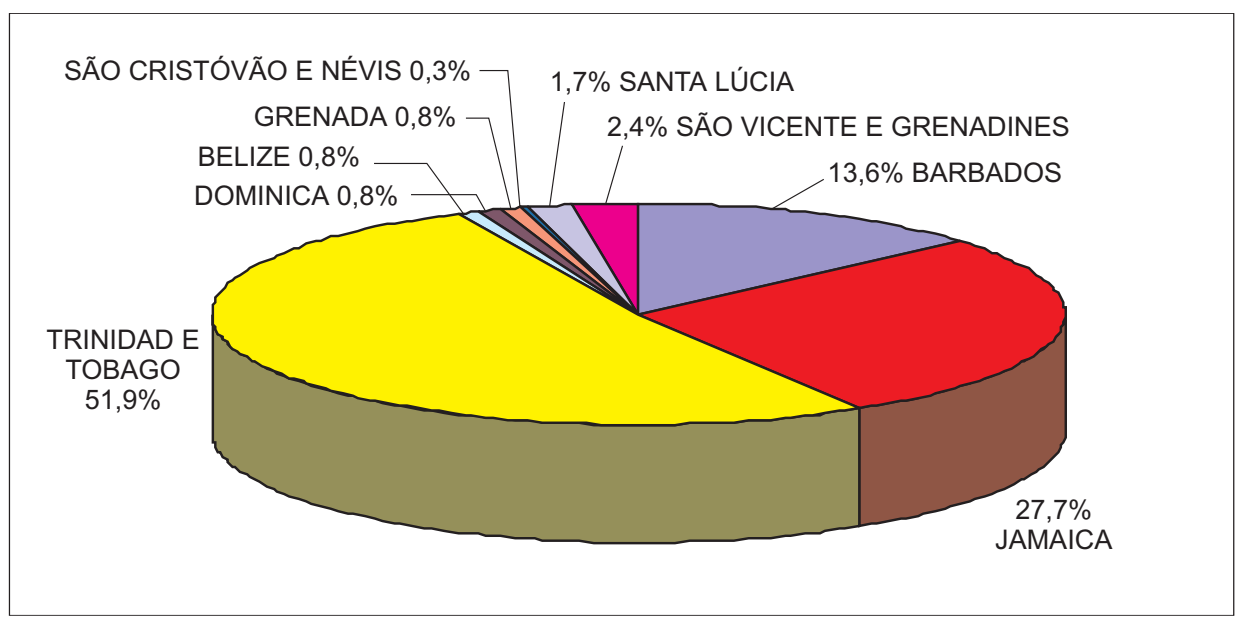

Nos Países Mais Desenvolvidos (incluindo Suriname e Guiana), provavelmente, esforços no sentido de estimular as exportações brasileiras para o CARICOM trariam mais resultado comercial, considerando-se o seu maior poder de compra e de re-exportação para os Países Menos Desenvolvidos. Em uma análise pragmática, por serem muito diminutos, os esforços para estimular o comércio com eles diretamente talvez não seriam vantajosos do ponto de vista custo/benefício.

São exemplos de pontos considerados importantes os interesse na importação nas áreas de tecnologia de uso de mão de obra intensiva, processamento de alimentos, equipamentos agrícolas e formação de recursos humanos. 
Quanto às importações brasileiras relativas a produtos do CARICOM, o quadro de concentração chega a seu ponto extremo. Segundo os dados da Secretaria do CARICOM, para o ano de 1997, 98\% do que foi importado pelo Brasil de países membros do bloco foi oriundo de Trinidad e Tobago, sendo a pauta composta basicamente de produtos derivados de petróleo e gás natural.

A situação de importação de outros países do CARICOM é um pouco mais delicada, já que o Brasil também produz a maioria dos produtos dos países da região. No caso da monocultura da exportação de bananas dos Países Menos Desenvolvidos, esses se encontram em posição virtualmente improvável de exportação de seus produtos para o Brasil, já que o Brasil já possui o suficiente para sua demanda interna. A situação só se reverteria se o custo de produção desses países fosse muito menor do que no Brasil, para que houvesse um interesse comercial concreto.

Os gráficos abaixo apontam para os dados da importação ${ }^{33}$ :

\section{Gráfico 3}

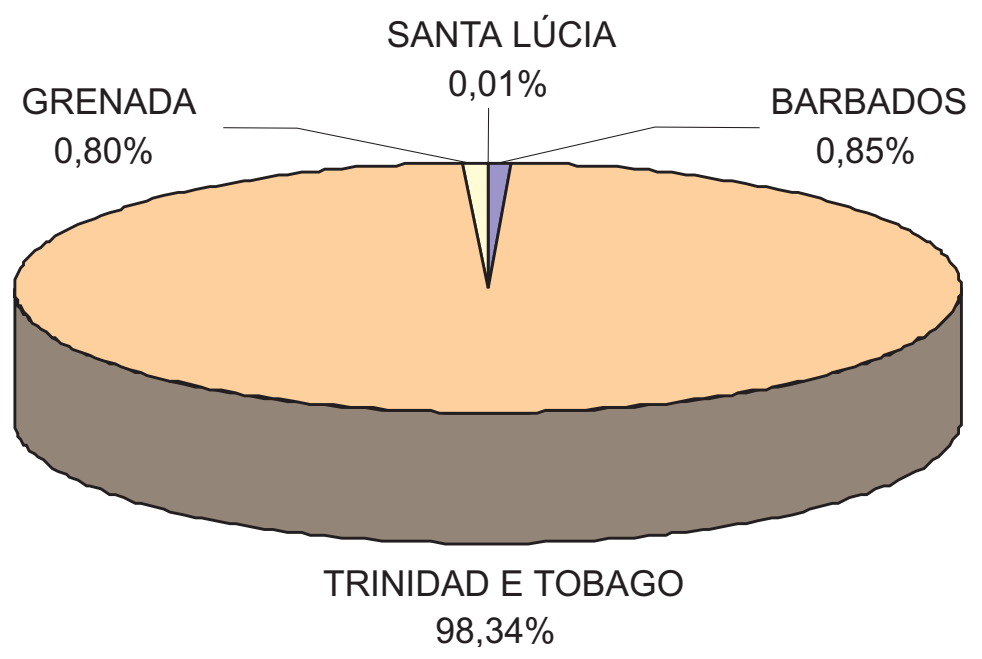




\section{Gráfico 4}

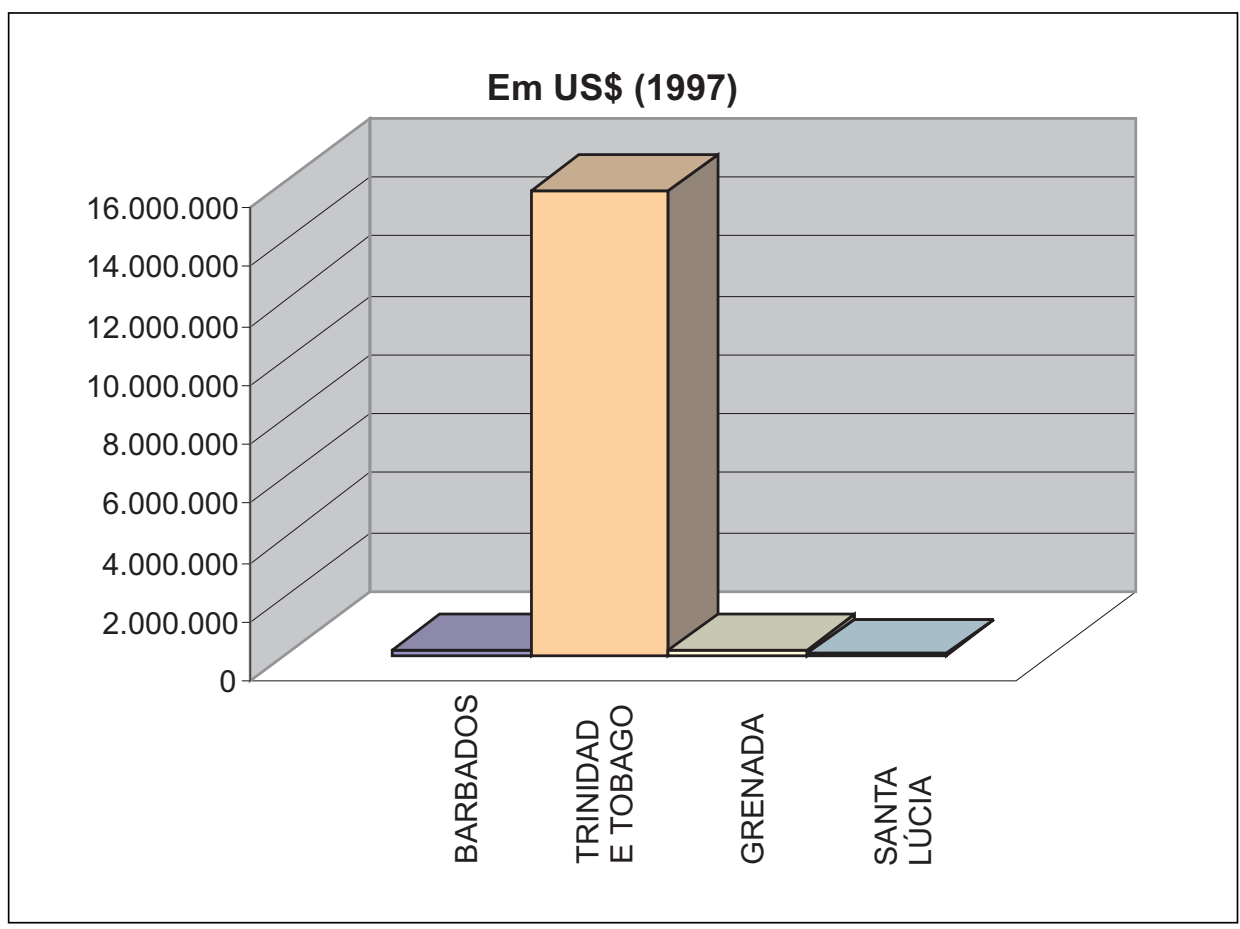

Foi muito bem colocado no Documento de Trabalho ${ }^{\circ} 1$ da Reunião entre os Embaixadores brasileiros na América Central e no Caribe (1994) que “(...) quaisquer investimentos na região, por pequenos que sejam, propiciarão significativos retornos, não apenas econômico-comerciais, mas sobretudo dividendos políticos”. ${ }^{34}$

Com essa perspectiva em mente, ao se observar o mercado do CARICOM, não se deve focalizar apenas as vantagens contábeis. O olhar do Governo Federal brasileiro deve ir mais além no seu posicionamento de investir tempo e atenção nessa região.

É válido especular que existe um ressentimento caribenho, e central americano também, em relação ao pequeno esforço e à falta de agressividade demonstrada pelo Brasil em efetivamente estimular o aumento desse ínfimo volume de comércio.

Como coloca o Documento de Trabalho da Reunião dos Embaixadores (1994) já mencionado, “(...) A intensificação das relações que se busca, uma vez viabilizada, ademais de resultar no aumento do intercâmbio econômico-comercial com a região, propiciaria a formação de um capital político de inestimável valor, sobretudo no que tange as pretensões do Brasil em foros multilaterais. A médio prazo pode vir a estimular, também, uma associação, cada vez mais ampla, 
entre os diferentes projetos de integração regional ora em formação na América Latina”35

\section{Conclusão}

Como se pôde observar, o relacionamento entre o Brasil e o CARICOM, bem como entre o Brasil e os países membros do CARICOM, tem sido bastante reduzido, especialmente no que diz respeito ao aspecto econômico. Segundo os Embaixadores brasileiros lotados no Caribe e na América Central em 1994, existe margem para intensificação dos contatos do Brasil com os países da região em praticamente todas as áreas de relacionamento. ${ }^{36}$ Essa opinião ainda é certa e infelizmente válida cinco anos após a elaboração do Documento.

Caso se queria colocar o mercado dos países no CARICOM como uma opção mais importante para o Brasil, ou pelo menos para regiões/estados brasileiros, ações concretas e direcionadas necessitam ser tomadas na seara do Governo Federal, o único a possuir competência para celebrar tratados, convenções e atos internacionais, por ter personalidade jurídica de direito internacional. Daí, operações como diminuição de tributos e uma política externa de comércio exterior que vislumbre o mercado em questão não podem ser iniciativa dos estados, mesmo que lhes seja interessante do ponto de vista econômico, dado o modelo federativo pátrio.

Talvez o país caribenho que esteja mais ativo em busca de aumentar suas relações comerciais com o Brasil seja Trinidad e Tobago. Esse país vem buscando contatos e negócios em especial com estados da região Norte/Nordeste brasileira.

Há a possibilidade de um acordo de turismo que beneficiaria a região amazônica, em que se buscaria incentivar empresas de turismo, que se direcionam à Trinidad e Tobago, bem como ao Caribe em geral, a incluírem visitas à Floresta Amazônica nos pacotes turísticos. Assim, existe a perspectiva de ambas as destinações turísticas saírem ganhando. Além disso, poder-se-á criar um “corredor” que facilitaria a ida e vinda de indivíduos entre as regiões brasileiras e caribenhas ${ }^{37}$.

Quanto à região Nordeste, a embaixada trinitária no Brasil parece bastante ativa na busca de novos mercados para seu gás natural, principal produto da ilha. Prova disso é o fato de que em Setembro de 1999, o Embaixador trinitário, Robert Tory, percorreu os estados do Pará, Ceará, Pernambuco e Bahia, estabelecendo contato com governos locais e empresários em busca de oportunidades.

O embaixador brasileiro em Trinidad e Tobago, Sr. Marcos Vinícius de Souza, também tem se esforçado para aumentar os laços entre o Brasil e o Caribe, colocando bastante esforço na intensificação das relações, especialmente entre Trinidad e Tobago e a região Norte/Nordeste brasileira, inclusive sugerindo a criação de um Núcleo de Estudos Caribenhos no estado do Ceará. 


\section{Notas}

1 LEITE (1978), pp. 5-23.

2 O Brasil foi aceito para a Associação na condição de observador em Dezembro de 1996.

3 Michael Manley e Edward Seaga foram ambos líderes Jamaicanos, tendo o primeiro governado de 1972 a 1980 e sendo Seaga seu sucessor. Diferentemente de Manley, Seaga possuía forte afinidade com o governo dos EUA e discordava da política de caráter socialista da Granada de Maurice Bishop.

4 VENTURA, Carlos Silva. p. 16.

5 POPE (1995), pp. 183-184.

6 WIARDA, Howard, pp. 205-6.

7 Posteriormente será comentada a posição brasileira no conflito

8 Cf. www.caricom.org

9 Cf. www.caricom.org

10 Uma possível causa desse baixo índice de investimentos em comércio e indústria no país se refere a problemas ligados à corrupção e ao tráfico ilegal de drogas, o que afastaria o investimento "produtivo".

11 Segundo dados de 1995, da Encyclopaedia Britannica, as Bahamas exportaram US\$176.000.000, dos quais 47,4\% eram na verdade reexportações. Dos 52,6\% de exportações domésticas, mais de $31 \%$ eram relativos à crayfish (um crustáceo, parecido com camarão). 81,1\% das exportações tiveram os Estados Unidos como destino, seguidos pela União Européia com 9,2\% e pelo Canadá com 1,9\%. As porcentagens relativas ao comércio intra-CARICOM foram muito pequenas.

12 Se essa justificativa procede ou não, caberia uma investigação mais aprofundada que, dado o tema proposto, não vem ao caso.

13 Encyclopaedia Britannica, Year in Review, 1998.

14 Existe literatura que trata dessas subdivisões. Nela se vê freqüentemente o uso das denominações MDC's (Most Developed Countries) e LDC's (Least Developed Countries).

15 A “questão da banana” tem rendido muitos debates já que os países produtores dentro do CARICOM teriam certas preferências comerciais concedidas pelos importadores europeus, por força do Acordo de Lomé. No entanto, os Estados Unidos vêm protestando, alegando a impossibilidade desse tratamento preferencial. A razão do protesto desse país se dá pelo fato dele possuir grandes plantações de banana na América Central, cujos países não pertencem ao Acordo, e cujo mercado consumidor também se encontra na Europa.

16 “Caribbean Sea”, Encyclopaedia Britannica Online, http://members.eb.com/bol/ topic?eu=117966\&sctn=7

17 Cf. www.sela.org

18 POPE (1995), p. 189. Vale ressaltar que o texto é de 1995 e menciona 45 milhões de pessoas. No entanto, incluindo o Haiti, com mais de 7 milhões de habitantes, e o crescimento demográfico da região desde o ano de publicação do livro, é possível que este número ultrapasse essa estimativa, alcançando 55 milhões de pessoas no caso da fusão dos dois blocos.

19 Cf. Site do Ministério das Relações Exteriores: www.mre.gov.br

20 Cabe lembrar que as disparidades dentro do CARICOM são significativas: o Haiti representa cerca de 50\% da população, seguido de Jamaica e Trinidad e Tobago, que contém algo entorno de $30 \%$ da população; esses dois últimos geram cerca de 50\% do PIB do bloco, enquanto que Guiana e Suriname abrangem 80\% do território. O CARICOM inteiro representa 1,2\% do território da América Latina e Caribe (reunidos). 
21

\section{Bibliografia}

ATKINS, G. Pope. Latin American in the International Political System. London: Westview Press, 1995.

BRYAN, Anthony. "The International Dynamics of the Commonwelth Caribbean: Challenges and Opportunities in the 1990s”. Journal of Interamerican Studies and World Affairs, v. 31, $\mathrm{n}^{\circ}$ 3, Fall 1989, pp 1-7.

"Dinamização das Relações do Brasil e do Caribe (Avalização preliminar das respostas às circulares telegráficas 19.914 e 20.673)”. Ministério das Relações Exteriores, Reunião de Embaixadores da América Central e do Caribe, Documento de Trabalho nº 1994.

FALCOFF, Mark. "Communism in Central America and the Caribbean”. IN: Wiarda, Howard: The Communist Challenge in the Caribbean and Central America. Washington D.C.: American Enterprise Institute for Public Policy Research, 1987. 
GILL, Henry. “CARICOM: origen, objetivos y perspectivas de integración en el Caribe. Integración Latino Americana, v. 191, Julho de 1993.

GONZALES, Anthony P. "Recent Trends in International Economic Relations of the Caribbean States. Journal of Interamerican Studies and World Affairs, v.31, n³, Fall 1989, pp 63-95.

GORDON, Lincoln. “The United States and the Caribbean”. IN: Kadt, Emanuel de: Patterns of Foreign Influence in the Caribbean. Oxford: University Press, 1972.

HAYES, Margaret Daly. Latin America and the U.S. National Interest:: A Basis for U.S. Foreign Policy - West View Special Studies on Latin America and the Caribbean. London: Westview Press, 1984

LEITE, Cleantho de Paiva Leite. “O Brasil e o Caribe”. Revista Brasileira de Política Internacional, $1^{\circ}$ e $2^{\circ}$ semestre de 1978, ano XXI, $n^{\circ} 81 / 84$, pp 5-22.

RICUPERO, Rubens. “O Brasil, a América Latina e os EUA desde 1930: 60 anos de uma relação triangular”. Em: Albuquerque, José Augusto Guilhon (org): Sessenta anos de Política Externa Brasileira 1930-90: Crescimento, Modernização e Política Externa. São Paulo: USP, 1996, vol.1, pp37-60

SERBIN, Andres. "Race and Politics: Relations between the English-Speaking Caribbean and Latin America”. Caribbean Affairs, Outubro/Dezembro 1989, vol.2, n. ${ }^{\circ} 4$

The Caribbean Basin Iniciative. San Fernando, Trinidad: People’s National Movement, Agosto 1982.

TRIGO, Alvaro Ramos. “CARICOM-MERCOSUR: Los beneficios de una mayor integración”. Capitulos SELA, n. 49, Janeiro/Março 1997, pág. 173-177

VIZENTINI, Paulo Fagundes. A Política do Regime Militar Brasileiro. Porto Alegre: Ed. da Universidade, UFRGS, 1998.

VALERO, Carlos Silva. “CARICOM: Pluralismo com Fronteras”. Nueva Sociedad, n. ${ }^{\circ}$ 67, Julho/ Agosto 1983, pp 15-18.

WILL, Marvin. “A Nation Divided: The Quest for Caribbean Integration”. Latin American Research Review, vol. 26, n. ${ }^{\circ} 2,1991$, pp 3-38.

WIARDA, Howard. "Impact of Granada in Central America”.

\section{Sites da Internet:}

www.acs-aec.org

www.britannica.com

www.caricom.org

www.mre.gov.br

www.sela.org

\section{Resumo}

O estudo das relações entre o Brasil e o CARICOM e outros países caribenhos tem sido historicamente negligenciado pelos analistas brasileiros, o que pode ser comprovado pelo número extremamente pequeno de publicações direcionadas ao assunto. Este artigo tenta proporcionar uma visão geral dos aspectos históricos, diplomáticos, econômicos e políticos, bem como uma perspectiva futura destas relações. 


\section{Abstract}

The study of the relationship between Brazil and the Caribbean Community, as well as with the Caribbean countries as a whole, have been historically left aside by Brazilian analysts, with an extremely limited amount of publications directed to the subject. This paper hopes to make an overview of historical, diplomatic, economic and political aspects and present events, as well as to offer a perspective of what the future might hold for the relationship between Brazil, the Caribbean Community and its member countries.

Palavras-chave: Política Externa do Brasil. Caribe. CARICOM. Relações Internacionais Brasileiras.

Key-words: Brazilian Foreign Policy. Caribe. Caribbean Community. Brazilian International Relations. 